\title{
Intra- and inter-annual variability in metabolism in an oligotrophic lake
}

\author{
David C. Richardson ${ }^{1}$ (D) Cayelan C. Carey $^{2} \cdot$ Denise A. Bruesewitz $^{3}$. \\ Kathleen C. Weathers ${ }^{4}$
}

Received: 6 November 2015/Accepted: 16 July 2016/Published online: 4 August 2016

(c) The Author(s) 2016. This article is published with open access at Springerlink.com

\begin{abstract}
Lakes are sentinels of change in the landscapes in which they are located. Changes in lake function are reflected in whole-system metabolism, which integrates ecosystem processes across spatial and temporal scales. Recent improvements in high-frequency open-water metabolism modeling techniques have enabled estimation of rates of gross primary production (GPP), respiration (R), and net ecosystem production (NEP) at high temporal resolution. However, few studies have examined metabolic rates over daily to multi-year temporal scales, especially in oligotrophic ecosystems. Here, we modified a metabolism modeling technique to reveal substantial intra- and interannual variability in metabolic rates in Lake Sunapee, a temperate, oligotrophic lake in New Hampshire, USA. Annual GPP and R increased each summer, paralleling increases in littoral, but not pelagic, total phosphorus concentrations. Storms temporarily decoupled GPP and R, resulting in greater decreases in GPP than R. Daily rates of GPP and R were positively correlated on warm days that had stable water columns, and metabolism model fits were
\end{abstract}

Electronic supplementary material The online version of this article (doi:10.1007/s00027-016-0499-7) contains supplementary material, which is available to authorized users.

David C. Richardson

richardsond@newpaltz.edu

1 Biology Department, SUNY New Paltz, 1 Hawk Drive, New Paltz, NY 12561, USA

2 Department of Biological Sciences, Virginia Tech, 1405 Perry Street, Blacksburg, VA 24061, USA

3 Colby College, 8800 Mayflower Hill Drive, Waterville, ME 04901, USA

4 Cary Institute of Ecosystem Studies, Box AB, Millbrook, NY 12545, USA best on warm, sunny days, indicating the importance of lake physics when evaluating metabolic rates. These metabolism data span a range of temporal scales and together suggest that Lake Sunapee may be moving toward mesotrophy. We suggest that functional, integrative metrics, such as metabolic rates, are useful indicators and sentinels of ecosystem change. We also highlight the challenges and opportunities of using high-frequency measurements to elucidate the drivers and consequences of intra- and inter-annual variability in metabolic rates, especially in oligotrophic lakes.

Keywords Gross primary productivity (GPP) $\cdot$ Net ecosystem production (NEP) - Respiration (R) . Metabolism · Storms - Lakes - Temporal variability

\section{Introduction}

Lake metabolism is an integrative measure of ecosystem function that represents the production and aerobic consumption of organic carbon (C); in many respects, metabolism defines the trophic state of the ecosystem (Odum 1956). Estimates of lake metabolism can integrate signals of complex anthropogenic changes within and beyond the broader lake catchment (Williamson et al. 2009; Adrian et al. 2009), and as such, are sentinels (sensu Williamson et al. 2009) of environmental change in lakes. Lake metabolism is typically summarized by three rates: gross primary production (GPP), ecosystem respiration $(\mathrm{R})$, and net ecosystem production (NEP; also known as net ecosystem metabolism). GPP is the rate at which phytoplankton, benthic algae, various prokaryotes, and submerged macrophytes create organic $\mathrm{C}$ from inorganic $\mathrm{C}$ using light energy via 
photosynthesis, $\mathrm{R}$ is the rate at which that organic $\mathrm{C}$ is respired, and NEP is the balance between rates of production and respiration in a lake. A negative NEP indicates that $\mathrm{R}$ exceeds GPP and suggests a use of external sources of organic $C$, whereas a positive NEP indicates that GPP exceeds $\mathrm{R}$, with the excess fixed $\mathrm{C}$ available for storage in the lake sediments, non-biological oxidation, or export downstream (Lovett et al. 2006). Thus, metabolism estimates can provide indices of change in biological production in a lake over multiple time scales, as well as indicate whether lakes are net heterotrophic (-NEP) or autotrophic (+NEP).

Traditionally, metabolism has been estimated directly from bottle incubations or diel oxygen fluctuations using a 'bookkeeping' calculation (Odum 1956; Cole et al. 2000; Staehr et al. 2010). Advances in high-frequency dissolved oxygen sensor technology (e.g., Staehr et al. 2012; Weathers et al. 2013), increased metabolism model complexity, and use of parametric statistical techniques (van de Bogert et al. 2007; Hanson et al. 2008) have improved the spatial and temporal resolution of metabolism estimates. These advances have enabled new discoveries about the role of lakes in the global C cycle (e.g., Solomon et al. 2013), controls on metabolism (Hoellein et al. 2013), and spatial variability of metabolism within lakes (Van de Bogert et al. 2012). Furthermore, these rapidly-developing techniques have facilitated investigation of the variability of metabolism at finely-resolved spatial (Klug et al. 2012; Van de Bogert et al. 2012) and temporal (Hanson et al. 2008; Solomon et al. 2013) scales.

New "open-water" metabolism modeling techniques are dependent on fitting high-frequency daily oxygen curves with a model that includes parameters representing rates of gross primary production and total respiration, as well as some empirical estimates of physical fluxes of oxygen across the water-air boundary. To date, most lake metabolism studies using these techniques have focused on temporal variation based on measurements made in the epilimnion and restricted to one year time periods (e.g., Carignan et al. 2000; Sadro et al. 2011; Klug et al. 2012; Solomon et al. 2013; Morales-Pineda et al. 2014), in part because the deployment of high-frequency sensors is a recent phenomenon (Weathers et al. 2013). In the few studies when metabolism was estimated across multiple years in lakes, rivers, or estuaries, metabolic rates were linked to anthropogenic nutrient loading (Uehlinger 2006) and climatic variation (Roberts et al. 2007; Staehr and Sand-Jensen 2007; Einola et al. 2011; Laas et al. 2012; Caffrey et al. 2014; Roley et al. 2014). Here, we expand upon these earlier studies to intensively investigate the patterns of metabolism over longer-term scales (i.e., $>5$ years) in a large, oligotrophic lake that has not experienced directional climate variation (Carey et al. 2014).
Many environmental factors control metabolic rates in lakes at different temporal scales. For example, at the daily scale, photosynthetically-active radiation (PAR) is one of the primary controls on GPP and NEP, as phytoplankton respond to the diel cycle of fluctuating PAR over $24 \mathrm{~h}$ (Hanson et al. 2006; Langman et al. 2010; Silsbe et al. 2015), whereas temperature is a primary control on $\mathrm{R}$ (Yvon-Durocher et al. 2012). Seasonal variability in metabolism could be driven by changes in temperature or light (Hanson et al. 2006; Langman et al. 2010; Laas et al. 2012), plankton abundance and succession (e.g., phytoplankton blooms, the zooplankton clear water phase), as well as by storms (Jennings et al. 2012; Klug et al. 2012; Staehr et al. 2012). For example, Klug et al. (2012) detected a decoupling of GPP and $\mathrm{R}$ in seven lakes in northeastern North America during and after Hurricane Irene in 2011, likely due to increased physical mixing and nutrient and organic matter entering the lakes from their catchments. At the inter-annual scale, variation in metabolic rates could be due to broader changes in climate or the catchment that alter subsidies of nutrients or organic matter. For example, if nutrient loads to a lake increase, the lake may exhibit increased GPP (Wetzel 2001), or, if the frequency and intensity of storms increase, GPP and R may become increasingly decoupled (e.g., Klug et al. 2012).

Oligotrophic lakes provide an interesting opportunity to study metabolism at different time scales. This is, in part, because of their high sensitivity to nutrient and organic matter loading (Wetzel 2001). It may be difficult to detect the first signals of eutrophication in an oligotrophic lake with weekly or monthly sampling of standard limnological trophic state indicators (e.g., chlorophyll $a$ concentrations, Secchi depth, nutrient concentrations; Carlson 1977). Incipient eutrophication may be better tracked using highfrequency GPP, R, and NEP. However, open-water metabolism models have not proven entirely effective for analysis of oligotrophic lake metabolism because models can sometimes predict oxygen concentrations that poorly match observed data (McNair et al. 2015). Further, due to subtle diel variation in oxygen concentrations in oligotrophic lakes, physical processes may overwhelm the biological signal. For example, in a global survey of metabolic rates across 25 lakes, two oligotrophic systems, Lake Sunapee, New Hampshire, USA and Sparkling Lake, Wisconsin, USA, had many days with near-zero estimates of GPP and R (Solomon et al. 2013). Traditional openwater metabolism models may need modification to capture diel fluctuations in GPP and $\mathrm{R}$ in lakes with low productivity (McNair et al. 2015).

Here, our overarching goal was to study the temporal variability in metabolism of oligotrophic Lake Sunapee, a deep, clear-water lake. Lake Sunapee has a unique, sevenyear record of high-frequency oxygen data, enabling 
examination of metabolism at daily, weekly, monthly, and annual time scales. We asked three questions: (1) How do GPP, R, and NEP vary at both intra- and inter-annual time scales in this oligotrophic lake? We predicted that GPP and $\mathrm{R}$ would generally be strongly coupled and low relative to rates estimated in mesotrophic and eutrophic lakes (Solomon et al. 2013) and that NEP would usually be negative, given low algal production (Hanson et al. 2004; Solomon et al. 2013). (2) What are the effects of storms on metabolic rates? We predicted that storms would decrease GPP and increase $\mathrm{R}$, thereby decoupling the two rates (Klug et al. 2012). (3) What environmental drivers are correlated with variability in metabolism at different time scales? At the daily scale, we predicted that increased mixing in the water column would reduce the magnitude of GPP, whereas PAR would increase GPP. We predicted that $\mathrm{R}$ would be linked to temperature (e.g., Yvon-Durocher et al. 2012) and that NEP would be negative (net heterotrophic) in a system with low algal biomass (Cole et al. 2000). Seasonally, we expected that storms would play a large role in driving GPP and $\mathrm{R}$ as described above, and annually, we expected that inter-annual variability in nutrient concentrations would be positively associated with GPP and R.

\section{Methods}

\section{Site description}

We examined multi-year metabolism dynamics in Lake Sunapee $\left(43^{\circ} 24^{\prime} \mathrm{N}, 72^{\circ} 2^{\prime} \mathrm{W}\right)$, an oligotrophic lake located in central New Hampshire, USA (Fig. 1). Lake Sunapee has a surface area of $16.6 \mathrm{~km}^{2}$, a volume of $1.59 \times 10^{9} \mathrm{~m}^{3}$, a mean depth of $11.2 \mathrm{~m}$, a maximum depth of $33.7 \mathrm{~m}$, a maximum fetch of $9.1 \mathrm{~km}$ (Carey et al. 2014) and a residence time of 3.1 years. The dimictic lake is ice-covered from December or January through March, April, or May (Bruesewitz et al. 2015) and exhibits thermal stratification in summer months with a maximum thermocline depth at $\sim 6-8 \mathrm{~m}$ depth (Carey et al. 2014). Lake Sunapee is considered a clear-water lake and summer epilimnetic dissolved organic $\mathrm{C}$ (DOC) concentrations are $<2.5 \mathrm{mg} \mathrm{L}^{-1}$ (Solomon et al. 2013). The Lake Sunapee catchment is $123 \mathrm{~km}^{2}$ with the majority of surface cover in forest (80\%), open water, and wetland (combined, $90 \%$ ) and small proportions of urban $(6 \%)$ and agricultural land use (4\%) (K. C. Weathers, unpubl. data).

\section{Buoy description}

The Lake Sunapee Protective Association (LSPA; lakesunapee.org) deployed a monitoring buoy associated with the Global Lake Ecological Observatory Network (GLEON;

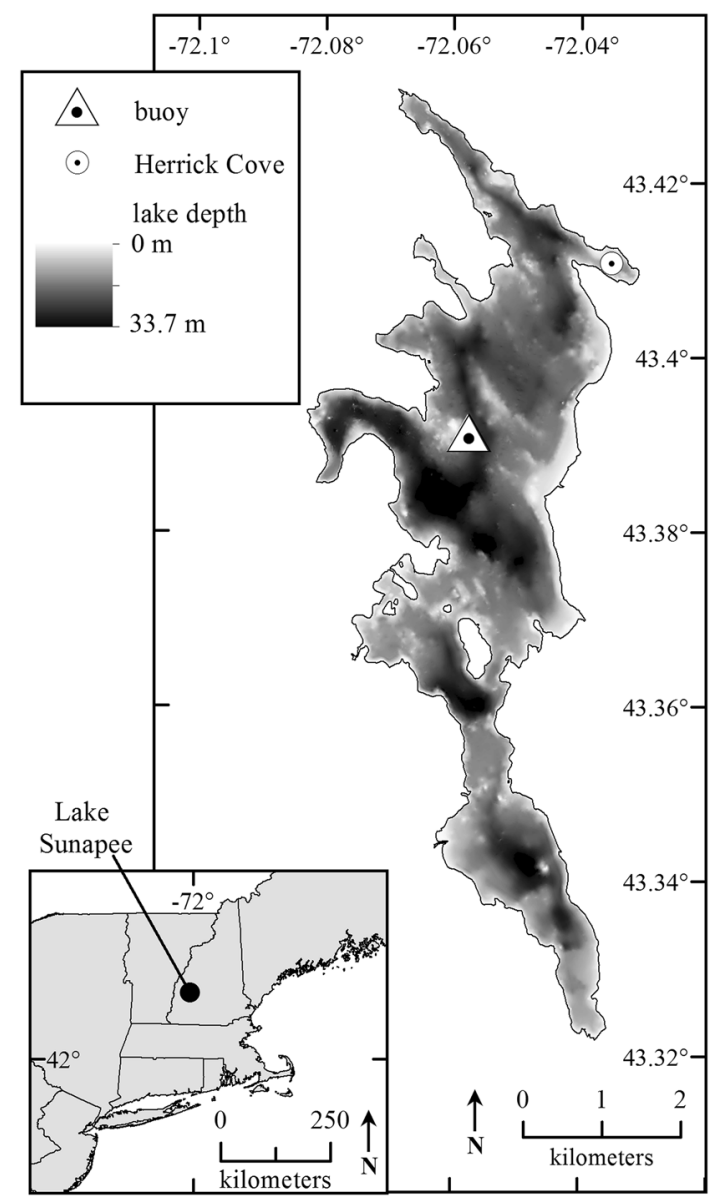

Fig. 1 Bathymetric map of Lake Sunapee, New Hampshire, USA. The triangle represents the location of the pelagic Lake Sunapee Protective Association GLEON buoy, and the circle denotes the location in Herrick Cove where littoral sampling occurred

gleon.org) near Loon Island lighthouse in late August 2007 (Fig. 1). The buoy location was chosen as representative of the lake, subject to boat navigation constraints (LSPA pers. comm.). The buoy was outfitted with multiple environmental sensors including air temperature, wind speed, water dissolved oxygen at $1 \mathrm{~m}$ depth, and a thermistor string from 1 to 14 m deep recording data every $10 \mathrm{~min}$ (see Klug et al. 2012; Bruesewitz et al. 2015 for all sensor descriptions). In most years, the buoy was removed from the lake in October or November to prevent ice damage and redeployed in April or May every year. We focused on the summer period from 20 May to 15 October 2007-2013, when the buoy was anchored at $\sim 15 \mathrm{~m}$ depth (Fig. 1). To make inter-annual comparisons, we used data for which we have a complete summer record from 2008 to 2013 because most data are missing from summer 2007 prior to buoy deployment. We did not use data from 2009 because the buoy had been severely damaged by ice in the preceding winter and data were not collected from 20 May to 29 July 2009. There were no other multi-day 
gaps in the dataset except for a 15-day period (27 August-10 September 2013) when the buoy was taken offline to add additional sensors.

\section{Data quality assurance and quality control process for streaming data}

All buoy sensor datasets were carefully examined using a standardized quality control/quality analysis process similar to that described in Bruesewitz et al. (2015). The DO sensor, as expected, was subject to drift throughout each year. Manually-collected monthly DO profiles with a HQ40 Hach multi-parameter meter (Hach Inc., Loveland, CO, USA) at the buoy site during 2007-2013 confirmed that the lake was at or near saturation at $1 \mathrm{~m}$ depth throughout the May-October monitoring period (LSPA, unpubl. data). To correct for sensor drift, we compared the measured buoy sensor DO with the saturated DO concentration calculated from the water temperature at $1 \mathrm{~m}$ depth and the mean atmospheric pressure for each day, following Weiss (1970). We subtracted those two DO concentrations to calculate a correction factor for all raw buoy sensor DO values for each day. The corrected DO values consistently compared well to the manually collected DO concentrations $(\mathrm{n}=18$ across all years, $r=0.69, p=0.002)$.

\section{Metabolism model}

Open-water modeling techniques fit a model with daily metabolic rates as parameters to observed curves of diel oxygen concentrations (Van de Bogert et al. 2007), which are usually small in oligotrophic lakes. Therefore, we modified existing modeling techniques to calculate metabolic rates for Lake Sunapee (see below). We also compared the modified modeling techniques to the traditional bookkeeping techniques.

DO dynamics were calculated for each day using a simple model (Odum 1956; Van De Bogert et al. 2007; Solomon et al. 2013):

$\frac{d O_{2}}{d t}=G P P-R+D$

where $\mathrm{dO}_{2} \mathrm{dt}^{-1}$ is the rate of change in the DO concentration at the $1 \mathrm{~m} \mathrm{DO}$ sensor, GPP is the mean daily rate of photosynthesis $\left(\mathrm{mg} \mathrm{O}_{2} \mathrm{~L}^{-1}\right.$ day $^{-1}$ ), $\mathrm{R}$ is the mean daily rate of respiration $\left(\mathrm{mg} \mathrm{O}_{2} \mathrm{~L}^{-1}\right.$ day $^{-1}$ ) and $\mathrm{D}$ is exchange of DO with the atmosphere (see Eq. 3 below). Every $10 \mathrm{~min}$ (the frequency of the sensor measurements), the DO dynamics were modeled as follows:

$Y_{t+1}=Y_{t}+g \times I_{t}-r+D_{t}+\gamma_{t}$

where $Y_{t+1}$ and $Y_{t}$ are the DO concentrations at time $t+1$ and $t$ respectively, $g$ is the parameter describing the average rate of photosynthesis per unit of irradiance at time $\mathrm{t}\left(I_{t}\right), r$ is the average rate of respiration, and $D_{t}$ is the atmospheric flux of DO, and $\gamma_{t}$ is the process error. The flux of oxygen between the lake water and the atmosphere $\left(D_{t}\right)$ was calculated at each 10-min time step as follows:

$D_{t}=d_{t} \times\left(-k_{t}\right) \times\left(Y_{t}-S_{t}\right) / z_{t}$

where $z_{t}$ is the mixed layer depth calculated from the water density gradient (Coloso et al. 2011); $d_{t}$ is a binary variable coded as 1 if the DO sensor is shallower than the mixed layer depth $\left(z_{t}\right)$, indicating that DO can exchange with the atmosphere, or 0 if the DO sensor is deeper than $z_{t}$ and atmospheric exchange is prevented;, $k_{t}$ is the piston velocity of $\mathrm{O}_{2}$ calculated for each 10-min time step using wind speed in an empirical model from Cole and Caraco (1998); and $S_{t}$ is the saturation concentration of DO given the water temperature and local average atmospheric pressure (Weiss 1970). For each day, $g$ and $r$ were scaled up to average daily rates (GPP and R). We assumed minimal diffusive exchange of DO between the epilimnion and hypolimnion, which is supported by multiple profiles of DO throughout our study period with an average difference of $1 \mathrm{mg} / \mathrm{L}$ of DO ( $n=26$ over the 7 year period) between the epilimnion and hypolimnion (Online Resource 1).

For 2007-2013, we modeled biological parameters (GPP and R) using an inverse open-water modeling technique (hereafter, "modeling" method) through the optimization of the statistical metabolism model (Eq. 2) with a maximum likelihood method (Van de Bogert et al. 2007; Hanson et al. 2008; Solomon et al. 2013). We acknowledge the potential for autocorrelated residuals because a smoothed model often cannot closely follow the irregular variability in a time series (see "Results" below for examples). Unlike the maximum likelihood technique, least-squares methods do not require the assumption of independent residuals when estimating parameter values. However, even if the residuals are autocorrelated, the maximum likelihood technique produces the same parameter estimates as least-squares methods if the residuals are assumed to be normally distributed with a mean of 0 (McNair et al. 2013). Additionally, modeling an autocorrelation term from the residuals resulted in non-autocorrelated residuals but did not change the estimates of metabolic rates (Van de Bogert et al. 2007). All analyses were conducted in the $\mathrm{R}$ statistical environment (v. 3.0.2, $\mathrm{R}$ Development Core Team 2013). GPP was modeled as a linear function of the above-lake irradiance (Hanson et al. 2008). If the mixed layer depth was above the DO sensor at $1 \mathrm{~m}$, then no atmospheric gaseous exchange (i.e., $D_{t}=0$ ) was considered for that time step (Solomon et al. 2013). We did not include temperature dependence in the model because we wanted to test for the effects of temperature on model fits (see below). We ran optimization code for each 
day in the months May to October to select the best modeled metabolic rates (GPP and R) for Eq. 2 using the Nelder-Mead optimization algorithm (Solomon et al. 2013) that minimized the negative log-likelihood between the modeled DO concentrations and the observed DO data (Van de Bogert et al. 2007). The fluxes calculated for each time step of the model were adjusted from mass flux per time step (10 min; Eq. 2) to mass flux per day (Eq. 1) by multiplying by the number of time steps in each day.

\section{Modifications to the metabolism model}

Despite parameter convergence and successful optimization of the metabolism model, the modeled DO did not always accurately predict observed DO curves. For example, on many days, daily GPP and R approached zero (e.g., $<10^{-6} \mathrm{mg} \mathrm{O}_{2} \mathrm{~L}^{-1} \mathrm{day}^{-1}$ ) and were not ecologically realistic rates, but mere artifacts of model optimization. To prevent the use of erroneous metabolism estimates in our analyses, we made several modifications to the metabolism model described by Solomon et al. (2013) and added a final check on model fits.

For each day starting $1 \mathrm{~h}$ before sunrise, the initial modeled DO concentration was calculated from the mean DO concentration from the first hour of measurements. This reduced the effect of initial conditions that may result from non-metabolism processes that lead to high frequency noise in the data. Second, we extended each modeled day from 24 (sunrise to sunrise) to $26 \mathrm{~h}$ by including $1 \mathrm{~h}$ before and after the initial and final sunrises. This extension was made to include dawn periods of low light prior to the calculated sunrise. Third, on several days, there was high variability in DO concentration immediately following sunrise for $1-5 \mathrm{~h}$, depending on the day. We could not clearly identify the mechanism for this atypical part of the diel curve, but it has been noticed by others and may be a result of microstratification, rapid surface temperature change, sunlight hitting the sensor from low angle, or biofouling (I. Jones and C. McBride, pers. comm.). We examined the individual metabolic rates and model fits without the $0-5 \mathrm{~h}$ following sunrise. If all early morning hours were included in the model for days that exhibited large variability in DO concentration, the modeled DO line was often erroneously flat, despite an observed diel curve. Importantly, when all early morning hours were included, the model failed to represent DO dynamics during the remaining $21 \mathrm{~h}$ of the day. We analyzed the difference in metabolism model fits for each day by sequentially removing $0,1,2,3,4$ and $5 \mathrm{~h}$ of data post-sunrise and found that the models with all $5 \mathrm{~h}$ excluded gave the best representation of observed DO dynamics (see "Results" below). To eliminate this source of data variability, which was not explicit in the daily metabolism model, we conservatively removed $5 \mathrm{~h}$ following sunrise for all days; the metabolic rates were estimated using the remaining $21 \mathrm{~h}$ of data. We present a sensitivity analysis and description of removing the $5 \mathrm{~h}$ following sunrise comparing to removing $0 \mathrm{~h}$ in the "Results" section.

Finally, we developed a protocol to exclude the remaining days with unrealistic GPP and R model estimates, based on visual assessment of plots of observed and modeled DO curves, the DO residuals, wind, and PAR. This protocol entailed independent examination of all of the data (observed and modeled), residuals, and fit statistics $\left(R^{2}, \mathrm{AICc}\right.$, and residual sums of squares) by three of the authors (DCR, CCC, and DAB), who used the data to assign the model fit for each day as acceptable or unacceptable (see "Results"). All three independent assessments of the model fits were compiled, and showed strong agreement (all pairwise ranks were highly correlated at $r>0.74$ ). If two or more authors determined that the model fit was unacceptable, then the GPP and R estimates for that day were conservatively removed from all future analyses. The independent assessments of this suite of data were necessary because numerical criteria alone often did not distinguish between acceptable and unacceptable fits, primarily as a result of the large number of data points used to generate each model fit. We note that this protocol ensured that the final dataset was conservative, excluding some model fits that would have been included with numeric criteria alone.

Following our metabolism analyses, we used logistic regression to determine which environmental conditions, including physical metrics of thermal stratification and weather (see "Drivers of daily metabolism" below), altered the likelihood of an acceptable or unacceptable metabolism model fit across the monitoring period. Acceptable and unacceptable model fits were coded as ' 1 ' or ' 0 ', respectively, from the analysis above. We focused on univariate relationships in logistic regression models between model fits and driver variables, which were aggregated at a daily scale as described above, because many of the driver variables were correlated with each other. We ranked the environmental predictors that exhibited corrected AIC (AICc) values that were within 11 units of the top model fit (Burnham et al. 2011). All logistic regressions were analyzed in JMP Pro (v. 11.0, SAS Institute, Cary, NC).

\section{Inter-annual trend analysis}

We calculated a new metabolism time series for each MayOctober year based on GPP and R temperature-corrected to $20{ }^{\circ} \mathrm{C}$ following Eq. 3 in Venkiteswaran et al. (2007). For each day, NEP was calculated as the difference between temperature-corrected GPP and R. The autocorrelation 
$(\mathrm{ACF})$ and partial autocorrelation (PACF) functions for all three metabolic rates for each year indicated significant autocorrelation, especially at the 1-3 day lag for all models. We then calculated autoregressive models separately for each year and each temperature-corrected metabolic rate using the auto.arima function in the $\mathrm{R}$ software forecast package (Hyndman and Khandakar 2007). We calculated the annual average by using a regression that fit a constant (the year's mean) and then modeled the residuals as an ARIMA process with the possibility for drift for nonstationary data (Hyndman and Athanasopoulos 2012). Following model selection for each metabolic rate and year, we recorded the annual mean and standard error. For 2010 to 2013, we used simple linear regression for each of the metabolic rates in the $\mathrm{R}$ statistical environment to assess inter-annual trends in metabolic rates.

\section{Drivers of daily metabolism}

We used the buoy data to calculate a number of physical lake metrics at the 10-min scale using thermistor data, including buoyancy frequency, lake number, and Schmidt stability of Lake Sunapee during the monitoring period (Read et al. 2011; Bruesewitz et al. 2015). We obtained precipitation and air temperature data for 20 May to 15 October for 2008-2013 from the National Climate Data Center (NCDC) website (ncdc.noaa.gov/cdo-web/search, last accessed on 14 October 2014) for Newport, New Hampshire, which is $10 \mathrm{~km}$ from the LSPA buoy. Barometric pressure, wind, and air temperature data from the Lebanon Airport (Lebanon, New Hampshire, $33 \mathrm{~km}$ from the LSPA buoy) were also compiled for the study period (Bruesewitz et al. 2015). All sub-data were then aggregated to the daily scale using multiple summary statistics, including central tendencies (mean, median) and dispersion (maximum, minimum, 25th and 75th quartiles, standard deviation, and coefficient of variation).

We used the suite of physical limnology and weather variables as correlates with daily metabolism across 2008-2013. We analyzed pairwise Spearman's rank-order correlations for each of the environmental variables to determine if they were significantly associated with GPP, $\mathrm{R}$, and NEP. For each metabolic rate, we selected the best model fits as the correlation with the lowest corrected Akaike Information Criterion (AICc) value and all of the correlations within 11 AICc units of the top model fit (Burnham et al. 2011).

We examined the coupling between GPP and R across all years using least squares linear regression. Because of the temperature dependence of metabolism processes, we standardized GPP and R to $20{ }^{\circ} \mathrm{C}$ as described above using the daily mean water temperature measured at the DO sensor to remove seasonal and daily variability in water temperature. We compared a 1:1 line with the observed GPP:R relationship using indicator variable regression (Kutner et al. 2004), in which the GPP:R line was coded as 0 and the $1: 1$ line was coded as 1 .

\section{Drivers of seasonal metabolism}

We identified two types of storms, high precipitation and wind events, using total daily precipitation $(\mathrm{mm})$ and maximum daily wind speed $\left(\mathrm{m} \mathrm{s}^{-1}\right)$ data from the National Climate Data Center (NCDC) website (ncdc.noaa.gov/cdoweb/search, last accessed on 14 October 2014). We identified the thresholds for storm events as the days that fell above the 95th percentile of the precipitation ( $n=938$ days) or wind ( $n=869$ days) distributions, following Jennings et al. (2012). The threshold for the classification of a storm was $19.5 \mathrm{~mm}$ of rain for a precipitation event and $11.2 \mathrm{~m} \mathrm{~s}^{-1}$ wind speed for a wind event. Any day with conditions above either or both of these thresholds was considered one of three types of storms: a precipitation event, wind event, or precipitation + wind event, if both precipitation and wind exceeded their thresholds on the same day.

Based on initial exploratory analyses, we found that storms caused relatively short-term effects (i.e., on average less than 3 days) on metabolic rates before returning to prestorm conditions. As a result, we tested the short-term (3 day) effects of storms on lake metabolism and the coupling of GPP and R. GPP, R, and NEP were averaged during the 3 days preceding each storm for pre-storm data; for post-storm data, we averaged the metabolic rates on the day of the storm and the two following days. We used paired t-tests to compare 3 day pre- and post-storm metabolic rates to determine if storms had a significant shortterm effect on metabolism and to see if there were differential effects of storms on GPP and R.

\section{Bookkeeping technique}

We used the traditional technique of estimating metabolism directly from DO concentrations (hereafter referred to as the "bookkeeping" method, also known as the "accounting" method; Odum 1956; Cole et al. 2000). In short, we computed NEP for each 10 min time period and assumed that only R, and not GPP, was occurring at night. We calculated GPP as NEP for the daylight hours after accounting for the mean $\mathrm{R}$ from the preceding and following nights (Cole et al. 2000).

\section{Drivers of annual metabolism}

The LSPA collected water samples at both littoral and pelagic sites during 1986-2013 for total phosphorus (TP) 
and chlorophyll $a$ analyses, and measured Secchi depth. All TP and chlorophyll $a$ samples were collected with a Van Dorn sampler four times every year: once in May, June, July, and August. Both epilimnetic pelagic and littoral samples were collected from just below the water's surface, and were processed with spectrophotometric methods with a chlorophyll $a$ detection limit of $0.2 \mu \mathrm{g} \mathrm{L}^{-1}$ and a TP detection limit of $5 \mu \mathrm{g} \mathrm{L}^{-1}$. Following New Hampshire Department of Environmental Services protocol, all TP samples $<5 \mu \mathrm{g} \mathrm{L}{ }^{-1}$ were rounded to $5 \mu \mathrm{g} \mathrm{L}^{-1}$ in their data records. We recognized that aggregation of these data would overestimate the true TP concentration, so to reduce potential bias from applying this detection limit, we aggregated TP data by year and reported the annual median epilimnetic TP and chlorophyll $a$ for 1986-2013. We examined changes in annual median epilimnetic TP, epilimnetic chlorophyll $a$, and Secchi depth between the pelagic site near the buoy with the littoral site that had the longest record of data collection, Herrick Cove at the northeastern inlet of Lake Sunapee (Fig. 1).

\section{Results}

\section{Metabolism model fits}

From the 2008-2013 dataset of May through October lakeyears, there were 836 days with buoy data; we excluded 108 days when the buoy was not collecting measurements. Out of the 836 days, we were able to calculate 568 daily metabolic rates (68\% of days) that met our criteria of acceptable model fits (Fig. 2). These acceptable daily metabolic rates included the removal of $5 \mathrm{~h}$ following sunrise, as described above.

To ensure that the removal of $5 \mathrm{~h}$ of morning DO data did not affect the interpretation of our results, we examined the effects of the data removal on the model parameters and metabolic rates (Fig. 3). First, when $0 \mathrm{~h}$ were removed, many estimates of daily GPP and $\mathrm{R}$ were $<0.01 \mathrm{mg} \mathrm{O} \mathrm{O}_{2}$ $\mathrm{L}^{-1}$ day $^{-1}$, or biologically insignificant (Fig. 3). By comparison, the removal of the $5 \mathrm{~h}$ had little or no effect on the modeled parameters and fits for 449/836 days (54\%; Fig. 3a, b). Consequently, the removal of the $5 \mathrm{~h}$ enabled an acceptable model fit with biologically meaningful GPP and $\mathrm{R}$ estimates for an additional 119 days (Fig. 3c, d). The remaining 268 days were eliminated as unacceptable model fits as described above because the residuals were not randomly distributed and large relative to other days, and removing 0 up to $5 \mathrm{~h}$ did not improve the fits (Fig. 3e, f) despite model convergence on GPP and R and indications from AICc criteria that both Fig. 3 and $f$ were optimal fits.

\section{Intra- and inter-annual metabolism trends}

Within each year, GPP and R simultaneously peaked twice, first in early June and the second in late summer, typically in early to mid-August (Fig. 2). Overall, both the variability and maximum GPP and $\mathrm{R}$ within a season increased over time, especially in 2013, but GPP and R were still low, with diel DO concentration oscillations generally $<1 \mathrm{mg} \mathrm{L}^{-1}$.
Fig. 2 Rates of gross primary production (GPP, open circles) and respiration $(\mathrm{R}$, closed circles, plotted on a negative scale to facilitate viewing) for Lake Sunapee during MayOctober in 2008-2013. In 2009, the buoy was damaged by ice in the winter and was removed from the ice for repairs until 29 July; in 2013, the buoy was taken offline for 2 weeks in late summer to add additional sensors

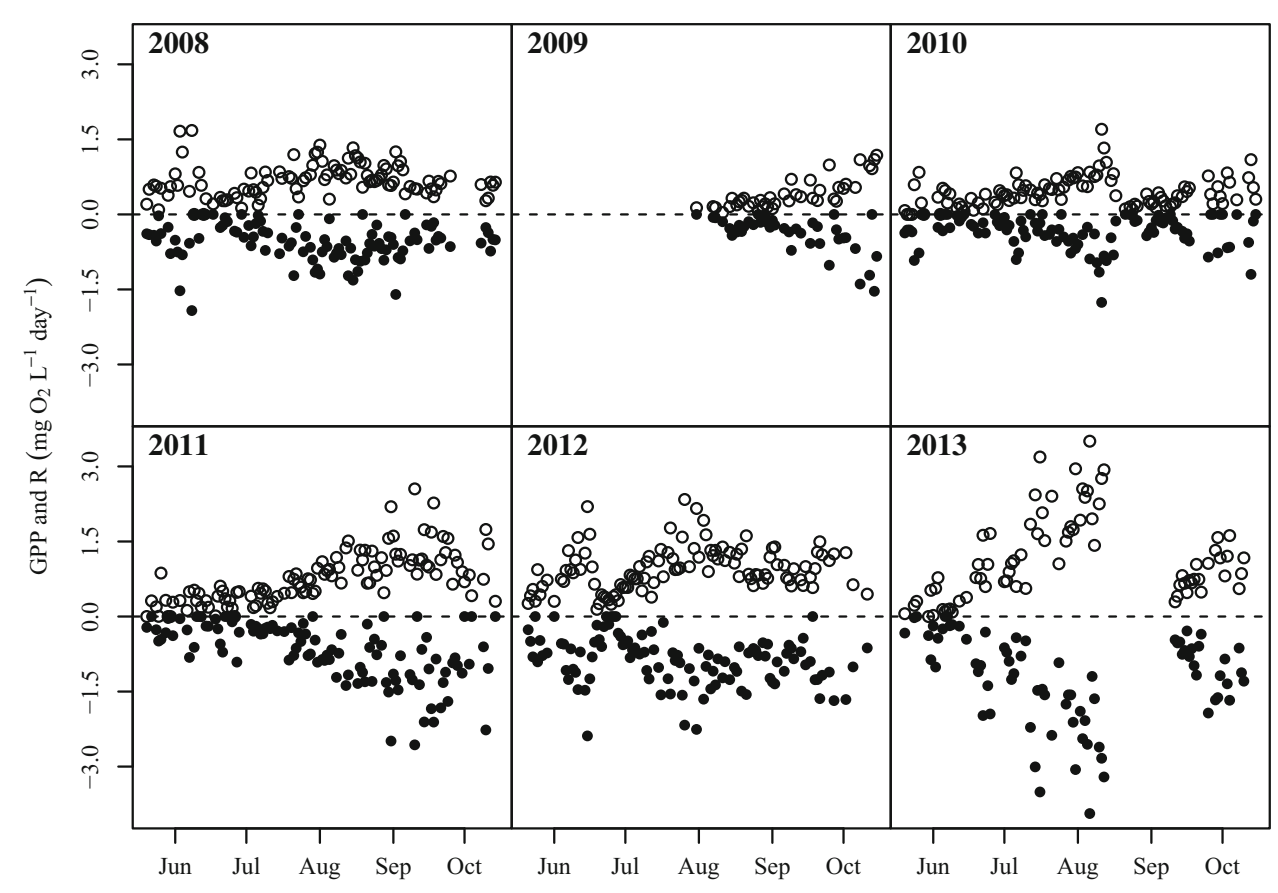




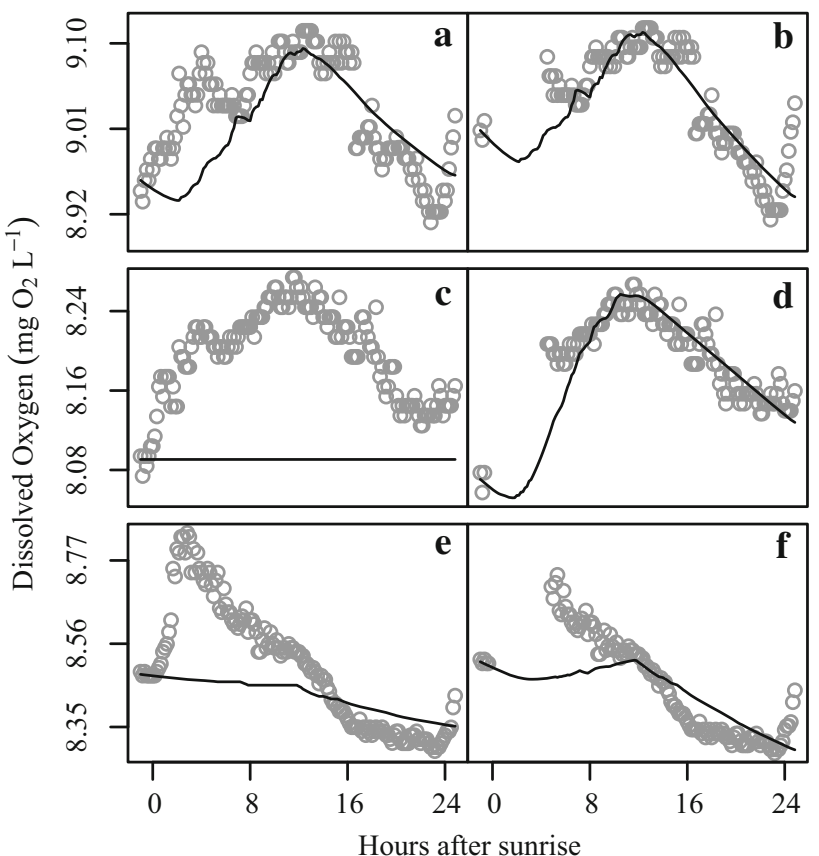

Fig. 3 Lake Sunapee observed dissolved oxygen (DO) data (grey open circles) and modeled fits (black line) for three example days: 20 June 2008 (a and b), 11 July 2009 (c and d), and 12 August 2011 (e and f). The first column (a, c, e) contains observed and modeled data with all available data included while the second column (b, d, f) has modeled fits for observed data with $5 \mathrm{~h}$ post-sunrise removed

Across years, median annual GPP ranged from 0.38 to $0.90 \mathrm{mg} \mathrm{O}_{2} \mathrm{~L}^{-1}$ day $^{-1}$ and mean annual $\mathrm{R}$ ranged from 0.26 to $1.05 \mathrm{mg} \mathrm{O}_{2} \mathrm{~L}^{-1}$ day $^{-1}$ (Fig. $4 \mathrm{a}, \mathrm{b}$ ). Since 2010, both the median and maximum GPP and $\mathrm{R}$ have increased, while the median annual NEP decreased from 0.12 to $-0.06 \mathrm{mg} \mathrm{O}$ $\mathrm{L}^{-1}$ day $^{-1}$. Using the annual means from the time series analyses, both GPP and R had significant increasing interannual trends from 2010 to 2013, but NEP did not (Table 1).

Over the length of the dataset, NEP indicated net autotrophy, although values were close to 0 and the linear trend was not statistically significant. In 2013, annual NEP was negative for the first year (Table 1). Over the whole time series, the maximum daily NEP was $0.91 \mathrm{mg} \mathrm{O}_{2}$ $\mathrm{L}^{-1}$ day $^{-1}$ and the minimum daily NEP was $-0.99 \mathrm{mg} \mathrm{O}$ $\mathrm{L}^{-1}$ day $^{-1}$ (Fig. 4). On a daily basis, Lake Sunapee was more often net autotrophic than heterotrophic, with NEP $>0$ for $66 \%$ of all days and NEP $<0$ for $34 \%$ of all days. When there were two consecutive days of metabolic rates available, NEP switched from autotrophy to heterotrophy or vice versa $39 \%$ of the time.

\section{Acceptable vs. unacceptable model fits: logistic regression analysis}

We identified 21 environmental variables that were significantly related to the likelihood of a metabolic rate being
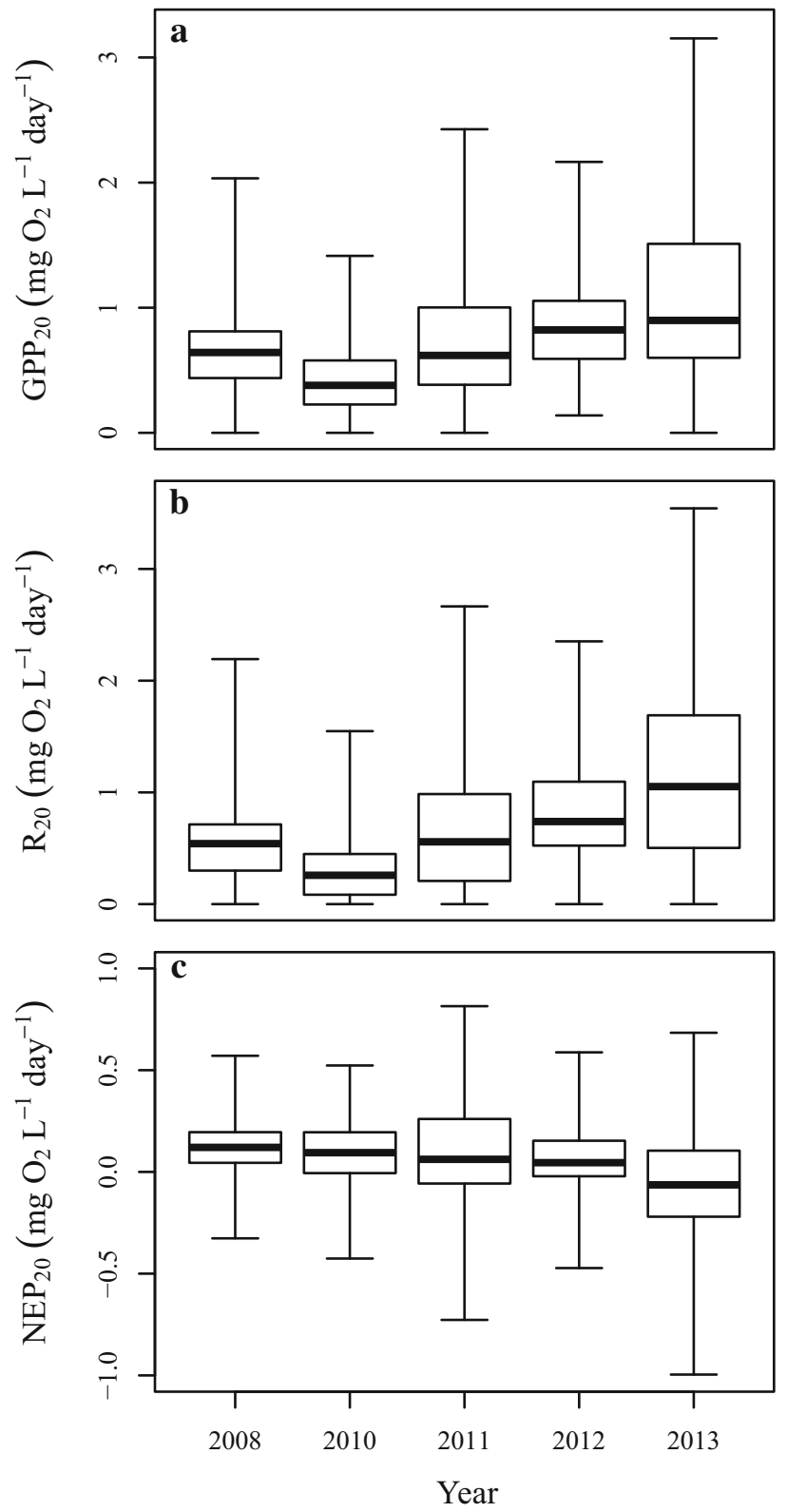

Fig. 4 Boxplots for a gross primary production $\left(\mathrm{GPP}_{20}\right)$ and respiration $\left(\mathrm{R}_{20}\right)$ and $\mathbf{b}$ net ecosystem production $\left(\mathrm{NEP}_{20}\right)$ for each year, all temperature corrected to $20{ }^{\circ} \mathrm{C}$. The dark line is the median, the box edges are the quartiles, and the whiskers are the max and min. Boxplots only include for years with comprehensive data for the entire May-October lake-year (2008, 2010-2013)

acceptable or unacceptable, as defined by being within 11 units of the minimum AICc value (Table 2). The 21 environmental variables were all related to Schmidt stability and metrics of air temperature, water temperature, and PAR.

In general, model fits were significantly more likely to be acceptable during warm, sunny days: the probability of an acceptable model fit increased with mean and maximum PAR and maximum air temperature measured at the buoy 
Table 1 Annual May to October means and standard errors (in $\mathrm{mg} \mathrm{O}_{2} \mathrm{~L}^{-1}$ day $^{-1}$ ) of the three metabolic rates in Lake Sunapee, NH, calculated from a regression that modeled the residuals as potentially arising from an autoregressive process

\begin{tabular}{llll}
\hline Year & $\mathrm{GPP}_{20}$ mean & $\mathrm{R}_{20}$ mean & $\mathrm{NEP}_{20}$ mean \\
\hline 2010 & $0.41 \pm 0.05$ & $0.32 \pm 0.05$ & $0.084 \pm 0.033$ \\
2011 & $0.70 \pm 0.28$ & $0.64 \pm 0.26$ & $0.087 \pm 0.016$ \\
2012 & $0.86 \pm 0.10$ & $0.84 \pm 0.12$ & $0.061 \pm 0.018$ \\
2013 & $0.97 \pm 0.34$ & $1.11 \pm 0.28$ & $-0.063 \pm 0.029$ \\
SLR eq. & $\mathrm{GPP}_{20}=0.19 \times$ year -374 & $\mathrm{R}_{20}=0.26 \times$ year -517 & $\mathrm{~N} . \mathrm{S}$. \\
SLR statistics & $\mathrm{F}_{1,2}=42.25, p=0.023$ & $\mathrm{~F}_{1,2}=277, p=0.004$ & $\mathrm{~F}_{1,2}=5.1, p=0.15$ \\
\hline
\end{tabular}

$\mathrm{GPP}_{20}$ is the rate of gross primary production, $\mathrm{R}_{20}$ is the rate of respiration, and $\mathrm{NEP}_{20}$ is the rate of net ecosystem production, all temperature corrected to $20{ }^{\circ} \mathrm{C}$. SLR indicates simple linear regression between the metabolic rate and year; N.S. indicates non-significant regression
Table 2 Significant daily drivers and Spearman correlation coeffecients $(\rho)$ of different metabolic rates for Lake Sunapee, NH: Gross primary production (GPP), respiration $(\mathrm{R})$, and net ecosystem production (NEP), as selected by the lowest corrected Akaike Information Criterion (AICc) for each variable

\begin{tabular}{|c|c|c|c|c|}
\hline Metabolic Rate & Environmental Variable & Variable daily summary statistic & $\rho$ & $\mathrm{AICc}$ \\
\hline NEP & Wind speed & Median & 0.44 & -1743.5 \\
\hline NEP & Wind speed & Mean & 0.42 & -1732.1 \\
\hline GPP & Lake number & Minimum & 0.30 & -782.6 \\
\hline GPP & Buoyancy frequency & Median & 0.47 & -776.8 \\
\hline $\mathrm{R}$ & Buoyancy frequency & Median & 0.44 & -715.6 \\
\hline
\end{tabular}

All environmental variables were aggregated to daily summary statistics. All Spearman correlations had $n=496$ days. Only the top model fits that were included within 11 of the minimum AICc units for each metabolic rate are presented. Variables are listed in descending order of best model fit

and the nearby airport. For example, when the mean daily PAR was $0.1 \mathrm{mM} \mathrm{cm}^{-2} \mathrm{~s}^{-1}$, there was a $62 \%$ probability of an acceptable fit, but when PAR increased to $0.5 \mathrm{mM} \mathrm{cm}^{-2} \mathrm{~s}^{-1}$, there was an $82 \%$ probability of an acceptable fit. Similarly, when the maximum daily air temperature was $10^{\circ} \mathrm{C}$, the probability of an acceptable fit was $59 \%$, but when the temperature increased to $25^{\circ} \mathrm{C}$, the probability of an acceptable fit increased to $78 \%$. The likelihood of an acceptable model fit was also positively related to higher standard deviations of the sensor temperature, air temperature, PAR, and delta air temperature and water temperature at the DO sensor within a day (Table 2).

\section{Drivers of daily metabolism}

Over the 2008-2013 time series, several environmental variables were highly correlated with each of GPP, R, and NEP based on AICc selection (Table 2). The minimum lake number and median buoyancy frequency, two metrics of thermal stability, were positively correlated to GPP (Table 2). Similarly, the median buoyancy frequency was positively correlated with $\mathrm{R}$, and the mean and median wind speed were both positively correlated with NEP (Table 2). Overall, the linear relationship between $20{ }^{\circ} \mathrm{C}$ temperature-corrected GPP and R was significant (regression equation provided in Fig. 5; $\mathrm{df}=566, p<0.0001$, $R^{2}=0.85$ ). The slopes of the observed GPP:R line $(1.06 \pm 0.019)$ and the $1: 1$ line were significantly different, as determined by a significant interaction of the dummy variable and GPP $(p=0.002)$. Below GPP $=1.80 \mathrm{mg}$ $\mathrm{O}_{2} \mathrm{~L}^{-1}$ day $^{-1}$, GPP was greater than $\mathrm{R}$, and above that rate, GPP was less than $\mathrm{R}$.

\section{Drivers of seasonal metabolism}

During May-October in 2008-2013, there were 30 precipitation events, 19 wind events, and two combined precipitation + wind events on days with corresponding metabolism data. Regardless of storm type, GPP decreased following storms (paired $t$ test; $t=-2.20, \mathrm{df}=50$, $p=0.03)$, but neither $\mathrm{R}(t=-0.56, \mathrm{df}=50, p=0.58)$ nor NEP $(t=-0.07, \mathrm{df}=50, p=0.94)$ exhibited consistent increases or decreases, indicating that $\mathrm{R}$ and GPP were decoupled in Lake Sunapee immediately following a storm.

In May-Oct 2011, the total precipitation amount $(852 \mathrm{~mm})$ and storm frequency were above normal for New Hampshire, with the third wettest May through October on record since 1895 (NOAA CLIMDIV 2015). 


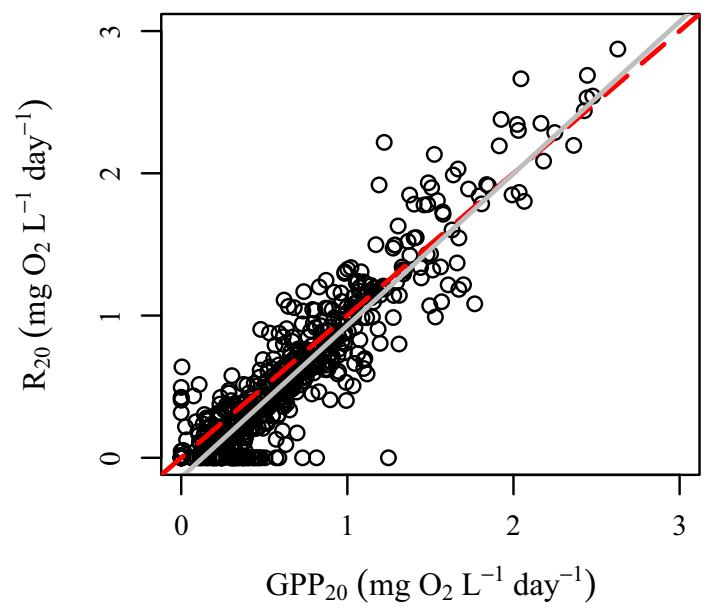

Fig. 5 Relationship between $\mathrm{GPP}_{20}$ and $\mathrm{R}_{20}$ (both rates temperaturecorrected to $20{ }^{\circ} \mathrm{C}$ ) for all metabolism estimates from 2007 to 2013 for Lake Sunapee. The grey line is the regression line $\left.\left(\mathrm{R}_{20}=1.06 \times \mathrm{GPP}_{20}-0.11\right), p<0.0001, R^{2}=0.85\right)$. The dotted line is the 1:1 line. One point was excluded from the graph for visualization $\left(\mathrm{GPP}_{20}=3.15, \mathrm{R}_{20}=3.54\right)$ but not from the analysis

Summer 2011 was marked by multiple large storms, namely Tropical Storms Irene and Lee, which passed over Lake Sunapee on 28-29 August and 5-8 September, respectively (Fig. 6; Klug et al. 2012). Tropical Storm Irene had high winds (up to $13 \mathrm{~m} \mathrm{~s}^{-1}$ sustained for $>1 \mathrm{~h}$ ) and delivered $101 \mathrm{~mm}$ of precipitation in a two-day period, with the first day identified as a combined precipitation + wind storm and the second day as a precipitationonly storm (Fig. 6a, b). Tropical Storm Lee delivered $85 \mathrm{~mm}$ of rain over a 4-day period, with two of the 4 days identified as precipitation events (Fig. 6a). The storms caused rapid decreases in lake thermal stability: Schmidt stability decreased by $31 \%$ following Irene and $36 \%$ following Lee (Fig. 6c). GPP and R responded to large storms with a lag before the maximum effect (Fig. 6d); for example, $\mathrm{R}$ was $\sim 0.6 \mathrm{mg} \mathrm{O}_{2} \mathrm{~L}^{-1}$ day $^{-1}$ for multiple days prior to Irene and reached a maximum of $2.5 \mathrm{mg} \mathrm{O}_{2} \mathrm{~L}^{-1}$ day $^{-1}$ on 31 Aug 2011, 3 days following the storm. Both of these storms exhibited a 14-day return time to conditions prior to Tropical Storm Irene.

\section{Drivers of annual metabolism}

While median epilimnetic TP concentrations at the pelagic buoy site did not significantly change over time (Fig. 7 , $\mathrm{p}=0.90$ ), we observed a significant increase in median TP at the littoral Herrick Cove site (Fig. 7; $\mathrm{TP}=0.0008 \times$ year $\left.-0.16 ; R^{2}=0.35, p=0.001\right)$. In the 1980s and 1990s, median littoral TP concentrations at Herrick Cove were generally at or below $5 \mu \mathrm{g} \mathrm{L}^{-1}$, the method detection limit. In the 2000s, however, the summer's median littoral TP concentration regularly exceeded

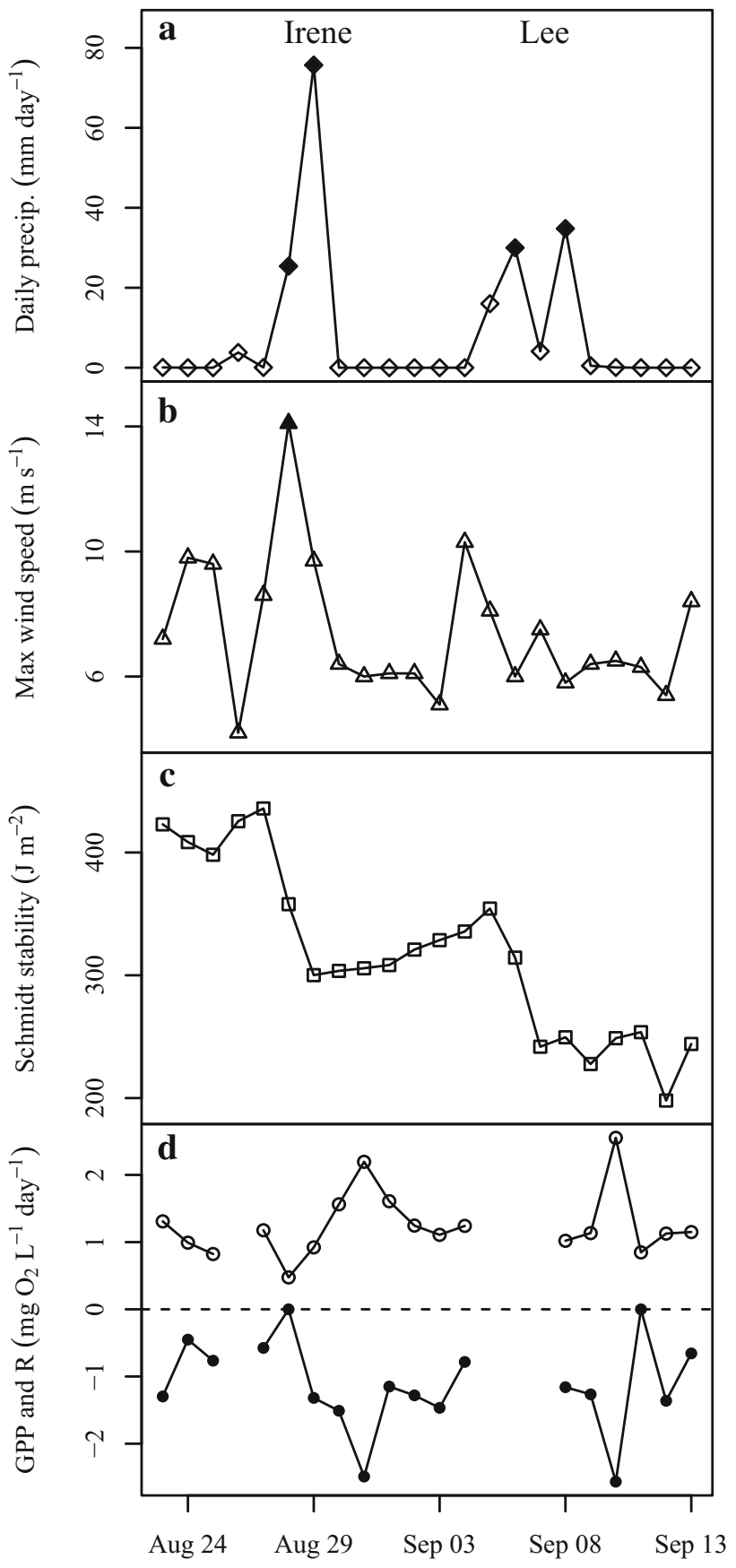

Fig. 6 a Daily total precipitation (daily precip.; diamonds), b daily maximum wind speed ( $\max$ wind speed; triangles), c daily mean Schmidt stability (Schmidt Stability; squares), and d GPP (rate of gross primary production; open circles) and R (rate of respiration; closed circles, plotted on a negative scale to facilitate viewing) for late August through early September 2011, Lake Sunapee. This time period coincides with when Tropical Storms Irene and Lee passed over the lake ( 2 and 4 days, respectively). In a and $\mathbf{b}$, filled symbols represent storms; see text for details on these calculations

the detection limit, up to $9 \mu \mathrm{g} \mathrm{L}{ }^{-1}$. At the pelagic site near the buoy, there were no statistically significant trends in epilimnetic chlorophyll $a$ or Secchi depth during 


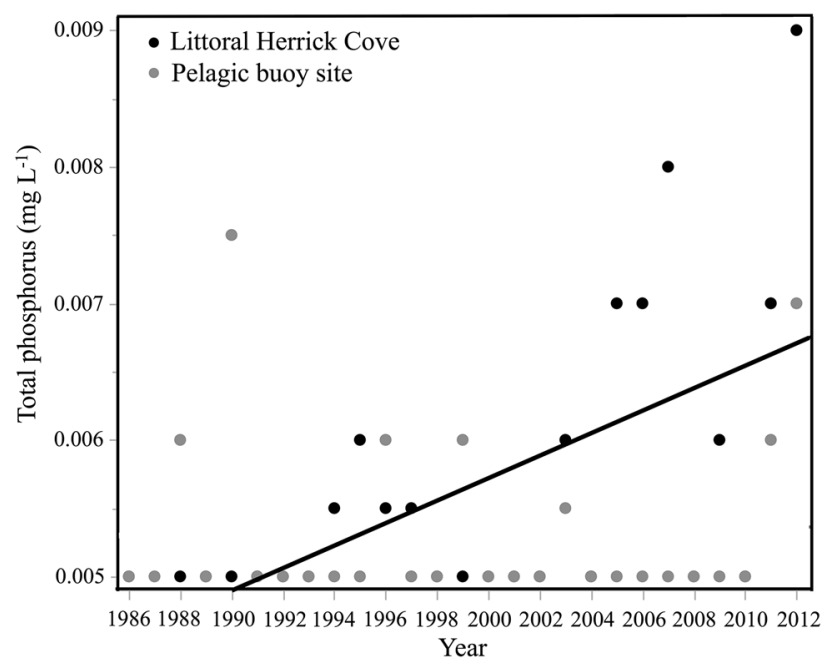

Fig. 7 Changes in median total phosphorus (TP) concentration at the littoral Herrick Cove site (black circles) and pelagic buoy site (grey circles) from 1986-2013, Lake Sunapee. There was no significant change in TP at the pelagic site $(p=0.90)$, but TP significantly increased in the littoral buoy site over time $\left(\mathrm{TP}=8.26 \times 10^{-5} \times\right.$ year $-0.16 ; R^{2}=0.35, p=0.001$ )

1986-2013 ( $p>0.05)$; during that time period, mean Secchi depth was $7.9 \pm 1.5(1 \mathrm{SD}) \mathrm{m}$. The median observed epilimnetic and hypolimnetic chlorophyll $a$ concentrations were $1.3 \pm 0.7(1 \mathrm{SD}) \mu \mathrm{g} / \mathrm{L}$ and $1.7 \pm 0.8 \mu \mathrm{g}$ $\mathrm{L}^{-1}$, respectively, and median Secchi depth was $8.2 \pm 1.2 \mathrm{~m}$ over the time series.

\section{Metabolism methods comparison}

Daily GPP from the metabolism model and bookkeeping method, and daily $\mathrm{R}$ from the metabolism model and bookkeeping method were both positively correlated ( $r \geq 0.74$, df $=566, p<0.001$, for each correlation), and were close to the 1:1 line (Fig. 8). However, the modeled rates were fit as variables that were forced to be $>0$ while the bookkeeping rates often had ecologically uninterpretable results $\left(<0 \mathrm{mg} \mathrm{O}_{2} \mathrm{~L}^{-1} \mathrm{day}^{-1}\right)$; for GPP, this occurred on $4 \%(24 / 568)$ of days, and for R, this occurred on $20 \%(116 / 568)$ of days. Further, the modeled fits had slightly higher rates, especially for R (Fig. 8).

\section{Discussion}

Despite the challenges of modeling metabolism in an oligotrophic lake, our analysis of 7 years of high-frequency data indicates that Lake Sunapee metabolism differed across multiple temporal scales. Interestingly, we observed that the intra-annual magnitude and variance of GPP and R increased during the study period (Fig. 2), suggesting the
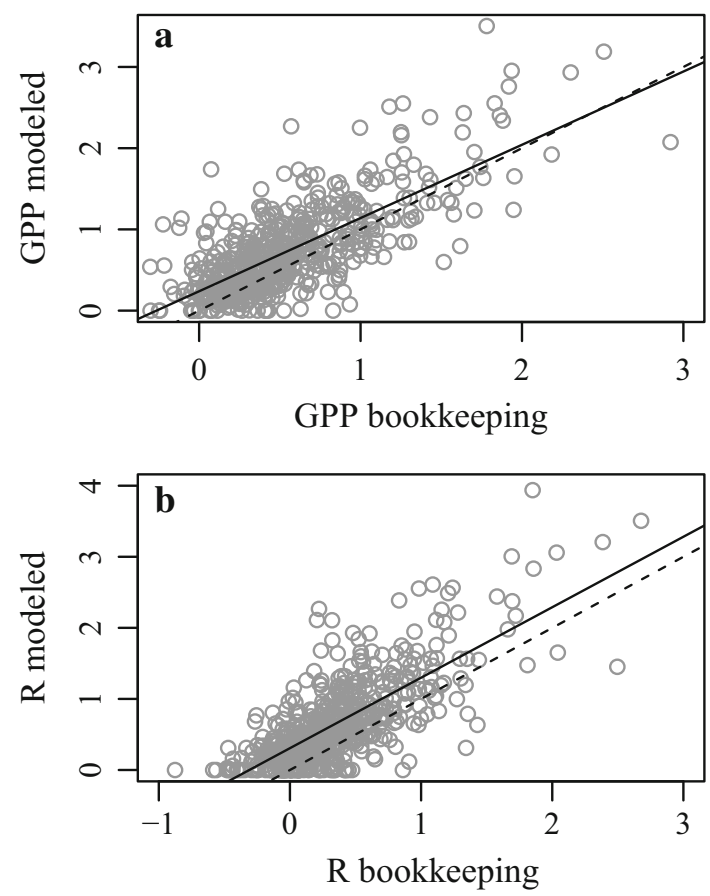

Fig. 8 Comparison between the modeled and bookkeeping methods for estimation of daily a GPP and $\mathbf{b}$ R. The dotted line is the 1:1 line and the black line is the least-squares linear regression fit

potential for the onset of a transition in trophic state from oligotrophy to mesotrophy in Lake Sunapee. Further, GPP and $\mathrm{R}$ were generally tightly coupled (Fig. 5), except immediately after storms, as is expected in a low-nutrient lake with small, but positive, NEP (Fig. 4). This tight coupling of GPP and $\mathrm{R}$ indicates that most $\mathrm{C}$ fixed in biomass is respired within the lake relatively quickly. Further, NEP was slightly negative in 2013 relative to small but positive NEP from previous years (Fig. 4). This suggests a transition from net autotrophy to heterotrophy in which $\mathrm{R}$ is increasing faster than GPP (Table 1), and may be an indicator of increased organic matter subsidies from the watershed.

\section{Challenges of modeling metabolism in a large, oligotrophic lake}

The most significant challenge of modeling metabolism in a low-nutrient lake is the fitting of the general metabolism model (Eq. 1). While the model is unable to capture all of the complex interacting ecosystem processes that control lake metabolism, it still has utility by providing valuable information. For example, identifying the environmental factors that affect model fit acceptability (e.g., Schmidt stability) helps inform our understanding of which parameters should be included in the model under different conditions. Part of the challenge for modeling metabolism 
in Lake Sunapee is that many estimates of metabolism in the literature are based on models built from mesotrophic or eutrophic lake ecosystems (Staehr et al. 2012; Hoellein et al. 2013), which typically exhibit large diel oscillations in DO concentrations that often exceed $5 \mathrm{mg} \mathrm{L}^{-1}$ (Solomon et al. 2013). By comparison, in oligotrophic Lake Sunapee, we commonly observed diel DO concentration swings $<1 \mathrm{mg} \mathrm{L}^{-1}$.

The relatively small diel DO changes in oligotrophic lakes makes it difficult to tease apart the effects of biological processes on DO concentrations from the effects of physical processes. In particular, a mechanistic understanding of how epilimnetic DO concentrations change in response to physical processes such as microstratification, upward movement of cold metalimnetic water, diffusion of oxygen across the metalimnion, and lateral mixing of surface waters from the wind become critical in development of metabolism estimates, and are likely related to the rapid changes in DO occurring in the early morning of Lake Sunapee (Fig. 3). If these physical processes overwhelm the biological signal in the diel DO curve, the metabolism model would not sufficiently capture real inputs to and outputs from the epilimnion to produce an acceptable model fit. Our results support this hypothesis: on warm, sunny days with stable stratification, the biological signal was clear relative to other physical processes, resulting in a higher likelihood of an acceptable model fit (Table 3).

We observed that the metabolism model was able to successfully estimate rates for up to 116 more days than the bookkeeping method, likely because the model integrates variability in rates throughout the day (McNair et al. 2015). While the bookkeeping approach allows for estimates of GPP and R without assuming any mathematical function, there is an overreliance on the differencing of successive DO concentrations (McNair et al. 2013). The modeling approach accounts for statistical error in the observed DO concentrations and gives objective estimates of GPP and R without the need for the assumption or use of $\mathrm{R}$ in the calculation of GPP and R (McNair et al. 2013), which may account for the differences between the two sets of results (Fig. 8).

Even with the open-water modeling approach, previous research has highlighted the challenges of using high-frequency buoy data to estimate whole-ecosystem GPP, R, and NEP. Both horizontal (littoral to pelagic) and vertical (depth of water column) positioning of DO sensors within a lake will influence metabolism estimates, due to a potentially high degree of spatial variability (Van de Bogert et al. 2012). We note that it is unlikely that the epilimnion of Lake Sunapee is completely homogenized longitudinally because of its complex basin morphometry (Fig. 1) and three-year hydraulic residence time. Long-term monitoring
Table 3 Significant environmental drivers of acceptable or unacceptable metabolism model fits, as determined by logistic regression for Lake Sunapee, NH

\begin{tabular}{|c|c|c|c|}
\hline Variable & Statistic & $\chi^{2}$ & $\mathrm{AICc}$ \\
\hline Schmidt stability & Stdev & 23.17 & 938.3 \\
\hline PAR & Mean & 22.18 & 939.2 \\
\hline PAR & Stdev & 21.48 & 939.9 \\
\hline Airport rel. humidity & Stdev & 15.71 & 940.0 \\
\hline PAR & 75th Q & 18.69 & 942.7 \\
\hline Air-water delta & Stdev & 18.34 & 943.1 \\
\hline Air temperature & Stdev & 18.10 & 943.3 \\
\hline Airport air temperature & $\operatorname{Max}$ & 15.51 & 944.1 \\
\hline PAR & Range & 16.35 & 945.1 \\
\hline PAR & Max & 16.35 & 945.1 \\
\hline Airport air temperature & Stdev & 10.40 & 945.3 \\
\hline Sensor temperature & Stdev & 15.97 & 945.4 \\
\hline Airport rel. humidity & Range & 13.84 & 945.8 \\
\hline Air temperature & 75th Q & 15.08 & 946.3 \\
\hline Air temperature & Max & 14.84 & 946.6 \\
\hline Airport rel. humidity & Min & 12.78 & 946.8 \\
\hline Sensor temperature & Range & 14.08 & 947.3 \\
\hline Air temperature & Range & 12.76 & 948.7 \\
\hline PAR & Median & 11.68 & 949.7 \\
\hline Airport wind speed & Stdev & 5.86 & 949.9 \\
\hline Air-water delta & Range & 11.37 & 950.0 \\
\hline
\end{tabular}

Variables were aggregated at the daily scale by several summary statistics and are listed in descending order of best model fit (i.e., increasing corrected AIC (AICc)). PAR refers to photosynthetically active radiation. Airport data were measured at the Lebanon Airport in Lebanon, New Hampshire and all other variables were measured at the buoy. For all regression analyses, $n=836$ days

has demonstrated that the hypolimnion remains oxic during the summer (Lake Sunapee Protective Association, unpubl. data); therefore, both the vertical exchange of nutrients from hypolimnion to epilimnion and lateral exchange during stratification exists but is likely to be small (Van De Bogert et al. 2007). However, the DO sensor for this study is at $1 \mathrm{~m}$ below the surface and, therefore, metabolic rates exclude a large portion of total lake volume; this omission may play a factor in poor model fits for some daily estimates of GPP and R. When averaged over longer periods of time in a large, deep lake such as Lake Sunapee (Fig. 3), metabolism at one central location likely integrates changes occurring across the lake, especially in the epilimnion, and acts as a sensitive indicator of changes in trophic status, despite day-to-day variability in metabolism (Fig. 2).

Future development of an open-water metabolism model for oligotrophic systems should refine the ability to elucidate the biological signal from small diel DO curves by considering both vertical and horizontal spatial variability as well as adding $\mathrm{CO}_{2}$ sensors or in situ incubations with 
higher sensitivity. Experimental designs that include clustered thermistors at shallow depths to measure microstratification or additional DO sensors in the metalimnion and hypolimnion would increase our ability to understand the processes occurring in the early morning hours in oligotrophic lakes like Lake Sunapee. Lack of such sensors to characterize the DO dynamics of the full water column remains a challenge for studying whole lake ecosystem metabolism. Metabolism models that incorporate data throughout the water column would likely be able to better reconcile the biological signal relative to physical changes in DO and lead to the estimation of depth-integrated metabolic rates (e.g., Obrador et al. 2014, McNair et al. 2015).

\section{Drivers of intra-annual metabolism trends}

Although daily GPP and R were largely coupled (Fig. 5), our data suggest that day-to-day variability in metabolic rates was primarily controlled by physical processes. Two physical factors (wind and rain) appear to be the main drivers of metabolism across multiple temporal scales, likely by altering lake stratification and mixing. Less wind and rain promote increased stability of the water column, as determined by buoyancy frequency, lake number, and Schmidt stability (Read et al. 2011). For all of these metrics, greater stability was positively correlated with GPP and R in Lake Sunapee (Table 2). Similarly, Staehr et al. (2010) found that higher thermal stability facilitates the growth of phytoplankton and correlates with increased GPP. However, unlike Staehr et al. (2010), mean daily PAR did not emerge as a predictor of GPP, possibly because we used both day and night PAR when calculating the daily mean with many 0 nighttime values lowering day to day differences.

In addition to the abiotic factors discussed above, biotic factors such as phytoplankton and zooplankton biomass can control daily GPP at sub-annual scales (Lampert and Wolf 1986; Staehr et al. 2010; Coloso et al. 2011). Throughout the monitoring period, we observed seasonal variation in GPP and $\mathrm{R}$ during May to October (Fig. 2). GPP and R consistently peaked in June and mid-August, which was likely tied to the seasonal succession of phytoplankton in the lake. Diatoms, in deep, north temperate lakes such as Sunapee, should increase immediately after ice-off in the spring, usually lasting through May until midJune, followed by a clear-water phase in late June (Reynolds 2006; Sommer 1986; Senerpont Domis et al. 2012). This pattern of algal growth and zooplankton grazing corresponds to the increase and rapid decrease of GPP in June, especially in 2008 and 2012 (Fig. 2).

Daily GPP and R were tightly coupled in Lake Sunapee over the 7 years of this study (Fig. 5): $70 \%$ of the daily variation in $\mathrm{R}$ was explained by daily variation in GPP, indicating a strong reliance of respiration on autochthonous $\mathrm{C}$ production by both autotrophic and heterotrophic organisms. This relationship represents one of the tightest couplings of daily GPP and R observed across a wide range of lakes around the world (Solomon et al. 2013). The DOC concentration in Lake Sunapee is low, which may help explain why it largely exhibits net autotrophy (Fig. 4c), especially in comparison to oligotrophic lakes with higher DOC concentrations that are heterotrophic (Cole et al. 2000; Hanson et al. 2004). Frequent switching between daily net autotrophy and heterotrophy might indicate a lag in which fixed $\mathrm{C}$ is respired a day or two later, suggesting that there may be an increased reliance on allochthonous $\mathrm{C}$ when $\mathrm{R}$ increases and exceeds GPP (Laas et al. 2012).

The scenario of de-coupling between GPP and R was most clearly observed during storms. We found that metabolism responded to storms but generally recovered quickly to pre-storm conditions. Similarly, Vachon and del Giorgio (2014) found that not all storms generated a shift in metabolism because storms are dynamic, and their effects could be masked by uncertainty in measurements or baseline within-day variability. We observed a decrease in GPP in the 3 days following a storm but not in R, which could result from a dilution of nutrients and organisms in the epilimnion from rain water and stream inflow (Abell and Hamilton 2014), decreasing light from lateral movement of organic matter from the littoral zone (Vachon and del Giorgio 2014), or deeper mixing of the epilimnion (Klug et al. 2012). Only extreme storms (i.e., Tropical Storms Irene and Lee) continued to alter GPP and R for longer than a week, with sustained increases in both GPP and $\mathrm{R}$ and a decoupling of GPP from R (Fig. 5). In the future, storms with intense precipitation and wind are likely to increase (Knutson et al. 2010), potentially generating even greater impacts on the overall annual metabolism balance of lakes.

\section{Inter-annual metabolism trends: an early indicator of a trophic status shift?}

At the annual scale, we observed a substantial increase in annual mean GPP and R and a decrease in NEP in Lake Sunapee over our seven-year study period (Fig. 2), despite no change in pelagic nutrient concentrations (Fig. 7) and no correlation with annual air temperatures. Because highfrequency DO concentrations integrate water column biology, chemistry, and physics, it may be a more informative - and comprehensive - sentinel of changing trophic state than TP concentrations or chlorophyll $a$ for oligotrophic lakes, where nutrient concentrations are generally at or near detection limits. 
The data presented here suggest that Lake Sunapee may be experiencing a trophic shift, which parallels increased observations of the large, colonial cyanobacterium Gloeotrichia echinulata in the lake (Carey et al. 2008, 2012). Gloeotrichia colonies were first observed in the water column of Lake Sunapee by local residents in 2004 (Carey et al. 2008; McGowan et al. 2014), and have dominated the phytoplankton assemblage every summer of our seven-year record (Carey et al. 2012, 2014). The large, buoyant colonies recruit in littoral sites and then are transported by currents and winds throughout the lake, creating patchy blooms (Carey et al. 2014), and potentially driving the increase in GPP at deep pelagic sites.

\section{Conclusions}

Seven years of daily metabolism data from Lake Sunapee illustrate how ecosystem metabolism is changing over daily, weekly, seasonal, and annual time scales. High-frequency data are crucial for detecting short and long-term ecosystem changes, especially in oligotrophic lakes, where metabolism changes are likely to be subtle and may be sensitive to shortterm changes in precipitation, wind, and thermal stratification. Our data suggest that a sensitive, functional, integrative metric such as metabolic rates-a sentinel process in lakescalculated from high-frequency measurements may be both a way to understand the response and resilience of lake ecosystems to short-term and long-term disturbances as well as a useful indicator for identifying the early stages of shifts from oligotrophy to mesotrophy.

Acknowledgments We thank the staff, Board of Trustees, and members of the Lake Sunapee Protective Association (LSPA), especially June and Peter Fichter, Robert Wood, and John Merriman, for their efforts in designing, building, deploying, and maintaining the LSPA buoy; for providing data for this project, including lake bathymetry; and for many hours of discussion about Lake Sunapee. This research was supported, in part, by the LSPA and the Frey Foundation, a Colby, Bates, and Bowdoin Mellon Faculty Mentoring Grant, the Virginia Tech Department of Biological Sciences, the SUNY New Paltz Biology Department, the Virginia Tech Institute for Critical Technology and Applied Science, and the Global Lakes Ecological Observatory Network (GLEON). We thank Amanda Lindsey and Bethel Steele for preparing Fig. 1 and, with Holly Ewing, for additional land use/land cover analyses; Ian Jones for discussions about physical limnological processes; Paul Hanson, Chris Solomon, Kathy Cottingham, and Chris McBride for discussions about metabolism; and Ryan Batt for statistical assistance. We thank two anonymous reviewers for suggestions that greatly improved earlier versions of this manuscript.

Open Access This article is distributed under the terms of the Creative Commons Attribution 4.0 International License (http://creative commons.org/licenses/by/4.0/), which permits unrestricted use, distribution, and reproduction in any medium, provided you give appropriate credit to the original author(s) and the source, provide a link to the Creative Commons license, and indicate if changes were made.

\section{References}

Abell J, Hamilton D (2014) Biogeochemical processes and phytoplankton nutrient limitation in the inflow transition zone of a large eutrophic lake during a summer rain event. Ecohydrology $8: 243-262$

Adrian R, O'Reilly CM, Zagarese H et al (2009) Lakes as sentinels of climate change. Limnol Oceanogr 54:2283-2297

Bruesewitz DA, Carey CC, Richardson DC, Weathers KC (2015) Under-ice thermal stratification dynamics of a large, deep lake revealed by high-frequency data. Limnol Oceanogr 60:347-359

Burnham K, Anderson D, Huyvaert K (2011) AIC model selection and multimodel inference in behavioral ecology: some background, observations, and comparisons. Behav Ecol Sociobiol 65:23-35

Caffrey J, Murrell M, Amacker K, Harper J, Phipps S, Woodrey M (2014) Seasonal and inter-annual patterns in primary production, respiration, and net ecosystem metabolism in three estuaries in the northeast Gulf of Mexico. Estuar Coast 37:222-241

Carey C, Weathers K, Cottingham K (2008) Gloeotrichia echinulata blooms in an oligotrophic lake: helpful insights from eutrophic lakes. J Plankton Res 30:893-904

Carey C, Ewing H, Cottingham K, Weathers K, Thomas R (2012) The occurrence and toxicity of the cyanobacterium Gloeotrichia echinulata in low-nutrient lakes in the northeastern United States. Aquat Ecol 46:395-409

Carey C, Weathers K, Ewing H, Greer M, Cottingham K (2014) Spatial and temporal variability in recruitment of the cyanobacterium Gloeotrichia echinulata in an oligotrophic lake. Freshw Sci 33:577-592

Carignan R, Planas D, Vis C (2000) Planktonic production and respiration in oligotrophic shield lakes. Limnol Oceanogr 45:189-199

Carlson R (1977) A trophic state index for lakes. Limnol Oceanogr 22:361-369

Cole J, Caraco N (1998) Atmospheric exchange of carbon dioxide in a low-wind oligotrophic lake measured by the addition of $\mathrm{SF}_{6}$. Limnol Oceanogr 43:647-656

Cole J, Pace M, Carpenter S, Kitchell J (2000) Persistence of net heterotrophy in lakes during nutrient addition and food web manipulations. Limnol Oceanogr 45:1718-1730

Coloso J, Cole J, Pace M (2011) Difficulty in discerning drivers of lake ecosystem metabolism with high-frequency data. Ecosystems 14:935-948

Einola E, Rantakari M, Kankaala P, Kortelainen P, Ojala A, Pajunen H, Mäkelä S, Arvola L (2011) Carbon pools and fluxes in a chain of five boreal lakes: a dry and wet year comparison. J Geophys Res Biogeosci 116:G03009. doi:10.1029/2010JG001636

Hanson P, Pollard A, Bade D, Predick K, Carpenter S, Foley J (2004) A model of carbon evasion and sedimentation in temperate lakes. Glob Change Biol 10:1285-1298

Hanson PC, Carpenter SR, Armstrong DE, Stanley EH, Kratz TK (2006) Lake dissolved inorganic carbon and dissolved oxygen: changing drivers from days to decades. Ecol Monogr 76:343-363

Hanson PC, Carpenter S, Kimura N, Wu C, Cornelius S, Kratz T (2008) Evaluation of metabolism models for free-water dissolved oxygen methods in lakes. Limnol Oceanogr Methods 6:454-465

Hoellein T, Bruesewitz D, Richardson D (2013) Revisiting Odum (1956): a synthesis of aquatic ecosystem metabolism. Limnol Oceanogr 58:2089-2100

Hyndman RJ, Athanasopoulos G (2012) Forecasting: principles and practice. OTexts. http://otexts.com/fpp/. Accessed 23 Oct 2015

Hyndman RJ, Khandakar Y (2007) Automatic time series forecasting: the forecast package for R. J Stat Softw. doi:10.18637/ jss.v027.i03http://dx.doi.org/10.18637/jss.v027.i03 
Jennings E, Jones S, Arvola L et al (2012) Effects of weather-related episodic events in lakes: an analysis based on high-frequency data. Freshwater Biol 57:589-601

Klug J, Richardson D, Ewing H et al (2012) Ecosystem effects of a tropical cyclone on a network of lakes in northeastern North America. Environ Sci Technol 46:11693-11701

Knutson T, McBride J, Chan J et al (2010) Tropical cyclones and climate change. Nat Geosci 3:157-163

Kutner M, Nachtsheim C, Neter J, Li W (2004) Applied linear statistical models, 5th edn. McGraw-Hill/Irwin, New York

Laas A, Noges P, Koiv T, Noges T (2012) High-frequency metabolism study in a large and shallow temperate lake reveals seasonal switching between net autotrophy and net heterotrophy. Hydrobiologia 694:57-74

Lampert W, Wolf H (1986) Cyclomorphosis in Daphnia cucullata: morphometric and population genetic analyses. J Plankton Res 8:289-303

Langman OC, Hanson PC, Carpenter SR, Hu YH (2010) Control of dissolved oxygen in north temperate lakes over scales ranging from minutes to days. Aquat Biol 9:193-202

Lovett G, Cole J, Pace M (2006) Is net ecosystem production equal to ecosystem carbon accumulation? Ecosystems 9:152-155

McGowan K, Westley F, Fraser EDG et al (2014) The research journey: travels across the idiomatic and axiomatic towards a better understanding of complexity. Ecol Soc 19:37

McNair JN, Gereaux LC, Weinke AD, Sesselmann MR, Kendall ST, Biddanda BA (2013) New methods for estimating components of lake metabolism based on free-water dissolved-oxygen dynamics. Ecol Model 263:251-263

McNair JN, Sesselmann MR, Kendall ST, Gereaux LC, Weinke AD, Biddanda BA (2015) Alternative approaches for estimating components of lake metabolism using the free-water dissolvedoxygen method. Fundam Appl Limnol 186:21-44

Morales-Pineda M, Cõzar A, Laiz I, Ubeda B, Galvez J (2014) Daily, biweekly, and seasonal temporal scales of $\mathrm{pCO}_{2}$ variability in two stratified Mediterranean reservoirs. J Geophys Res Biogeosci 119:509-520

NOAA's Gridded Climate Divisional Dataset (CLIMDIV) (2015) Temp, precip, and drought subset. NOAA National Climatic Data Center

Obrador B, Staehr PA, Christensen JP (2014) Vertical patterns of metabolism in three contrasting stratified lakes. Limnol Oceanogr 59:1228-1240

Odum HT (1956) Primary production in flowing waters. Limnol Oceanogr 1:102-117

R Development Core Team (2013) R: A language and environment for statistical computing [Internet]. R Foundation for Statistical Computing. http://www.r-project.org. Accessed 3 Aug 2016

Read J, Hamilton D, Jones I, Muraoka K, Winslow L, Kroiss R, Wu C, Gaiser E (2011) Derivation of lake mixing and stratification indices from high-resolution lake buoy data. Environ Modell Softw 26:1325-1336

Reynolds C (2006) Ecology of phytoplankton. Cambridge University Press, United Kingdom

Roberts B, Mulholland P, Hill W (2007) Multiple scales of temporal variability in ecosystem metabolism rates: results from 2 years of continuous monitoring in a forested headwater stream. Ecosystems 10:588-606

Roley SS, Tank JL, Griffiths NA, Hall RO Jr, Davis RT (2014) The influence of floodplain restoration on whole-stream metabolism in an agricultural stream: insights from a 5-year continuous data set. Freshw Sci 33:1043-1059

Sadro S, Melack M, MacIntyre S (2011) Spatial and temporal variability in the ecosystem metabolism of a high-elevation lake: integrating benthic and pelagic habitats. Ecosystems 14:1123-1140

Senerpont Domis LN, Elser JJ, Gsell AS et al (2012) Plankton dynamics under different climatic conditions in space and time. Freshwater Biol 58:463-482

Silsbe G, Smith R, Twiss M (2015) Quantum efficiency of phytoplankton photochemistry measured continuously across gradients of nutrients and biomass in Lake Erie (CA, US) is strongly regulated by light but not by nutrient deficiency. Can J Fish Aquat Sci 72:1-10

Solomon C, Bruesewitz D, Richardson D et al (2013) Ecosystem respiration: drivers of daily variability and background respiration in lakes around the globe. Limnol Oceanogr 58:849-866

Sommer U (1986) The periodicity of phytoplankton in Lake Constance (Bodensee) in comparison to other deep lakes of central Europe. Hydrobiologia 138:1-7

Staehr PA, Sand-Jensen K (2007) Temporal dynamics and regulation of lake metabolism. Limnol Oceanogr 52:108-120

Staehr P, Bade D, Van de Bogert M, Koch G, Williamson C, Hanson P, Cole J, Kratz T (2010) Lake metabolism and the diel oxygen technique: state of the science. Limnol Oceanogr Methods 8:628-644

Staehr P, Testa J, Kemp W, Cole J, Sand-Jensen K, Smith S (2012) The metabolism of aquatic ecosystems: history, applications, and future challenges. Aquat Sci 74:15-29

Uehlinger U (2006) Annual cycle and inter-annual variability of gross primary production and ecosystem respiration in a floodprone river during a 15-year period. Freshwater Biol 51:938-950

Vachon D, del Giorgio P (2014) Whole-lake $\mathrm{CO}_{2}$ dynamics in response to storm events in two morphologically different lakes. Ecosystems 17:1338-1353

Van De Bogert M, Carpenter S, Cole J, Pace M (2007) Assessing pelagic and benthic metabolism using free water measurements. Limnol Oceanogr Methods 5:145-155

Van de Bogert M, Bade D, Carpenter S, Cole J, Pace M, Hanson P, Langman O (2012) Spatial heterogeneity strongly affects estimates of ecosystem metabolism in two north temperate lakes. Limnol Oceanogr 57:1689-1700

Venkiteswaran J, Wassenaar L, Schiff S (2007) Dynamics of dissolved oxygen isotopic ratios: a transient model to quantify primary production, community respiration, and air-water exchange in aquatic ecosystems. Oecologia 153:385-398

Weathers K, Hanson P, Arzberger P et al (2013) The global lake ecological observatory network (GLEON): the evolution of grassroots network science. Limnol Oceanogr Bull 22:71-73

Weiss RF (1970) Solubility of nitrogen, oxygen and argon in water and seawater. Deep-Sea Res 17:721-735

Wetzel R (2001) Limnology, 2nd edn. Academic Press, Massachusetts

Williamson E, Saros J, Vincent W, Smol J (2009) Lakes and reservoirs as sentinels, integrators, and regulators of climate change. Limnol Oceanogr 54:2273-2282

Yvon-Durocher G, Caffrey J, Cescatti A et al (2012) Reconciling the temperature dependence of respiration across timescales and ecosystem types. Nature 487:472-476 